\title{
Proyecto de Investigación e Intervención en el Conjunto de Retablos y Bienes Culturales de la Capilla Doméstica de la Iglesia de San Luis de los Franceses, Sevilla
}

\begin{abstract}
Introducción
En el marco del acuerdo suscrito entre la Consejería de Cultura de la Junta de Andalucía y la Excelentísima Diputación Provincial de Sevilla se está llevado a cabo en el seno del Centro de Intervención del Instituto Andaluz del Patrimonio Histórico ( I.A.P.H.) el Proyecto de Investigación e Intervención del conjunto de retablos y bienes muebles de la Capilla Doméstica de la Iglesia de San Luís de los Franceses de Sevilla.
\end{abstract}

Este proyecto continua en la línea de investigación e intervención de retablos abierta por el I.A.P.H. con el retablo del Descendimiento de la Cruz, el retablo de los Santos Juanes de la Capilla Real de Granada y que continúa en la actualidad con en el retablo de los Genoveses de la Catedral Vieja de Cádiz; a estas actuaciones se suma el Proyecto que hoy presentamos.

La metodología defendida por el I.A.P.H. en el desarrollo de sus intervenciones en bienes culturales se basa en la premisa hoy día aceptada por todas las Instituciones que dedican su actividad a la Investigación y Conservación del Patrimonio Cultural "conocer para intervenir" y tiene como objetivo individuar los factores de riesgos, definir las características técnicas y constructivas y realizar aquellas investigaciones y pruebas necesarias que permitan delimitar el alcance de la intervención, los criterios de actuación, los tratamientos y el importe económico de la intervención en respuesta a las necesidades demandas por la propia obra.

Esta metodología requiere que de forma previa a la definición del proyecto de intervención, se lleve a cabo un proyecto de investigación, cuyos resultados definan el contenido y el alcance de la actuación. Desde el I.A.P.H. entendemos que este paso previo, el proyecto de investigación, es una herramienta válida y necesaria para poder plantear de forma correcta la intervención en bienes culturales.

Esta metodología aplicada al caso concreto de S. Luís de los Franceses, intenta por un lado profundizar en las tres vertientes básicas del conocimiento aplicado a la intervención:
- Investigación.

- Acción interdisciplinar.

- Definición de los criterios teórico-prácticos de intervención.

\section{El Proyecto de San Luis de Los Franceses}

La Iglesia de S. Luís de los Franceses, propiedad de la Excelentísima Diputación Provincial de Sevilla, aloja en su interior uno de los conjuntos retablísticos más importantes de comienzos del siglo XVIII de la región andaluza, destaca por ser un conjunto uniforme, no sólo porque todos ellos responden a un mismo taller, sino también porque pertenecen a un mismo estilo.

Este proyecto contempla además de la intervención en el conjunto de los siete retablos de la iglesia, el conjunto de bienes culturales que decoran los techos y paramentos de la Capilla Doméstica. En síntesis una diversidad de bienes culturales, no sólo en cuanto a tipología sino también en cuanto a materiales y técnicas de ejecución.

El Proyecto de Investigación e Intervención definido para estos bienes culturales, coincide plenamente la con la concepción actual que de la intervención en bienes culturales se plantea desde Instituciones similares al I.A.P.H. en el panorama nacional e internacional. Entendida la intervención no sólo como la realización de aquellas operaciones que se realizan directamente sobre el bien, sino también, la ejecución de aquellas que requiere el entorno o su contexto para proporcionar un medio adecuado para su supervivencia, su preservación temporal y mantenimiento. Esto sólo se puede abarcar planteando una fase de investigación cognoscitiva que contemple ambas vertientes y en particular el binomio contenido-continente.

El proyecto de San Luís de los Franceses contempla los siguientes estudios y actuaciones:

- Estudio medioambiental del continente arquitectónico
- Conocimiento técnico-material de las obras y de su estado de conservación.

- Diagnóstico de los bienes culturales, determinación y localización de las alteraciones y registro gráfico

- Realización de estudios científicos destinados a la identificación material de los componentes, y a la evaluación de los productos de alteración de los tratamientos.

- Investigación de carácter histórico-artístico.

- Definición de los criterios de intervención a aplicar.

- Puesta a punto de las técnicas y niveles de: consolidación, fijación, limpieza, reintegración, etc.

- Descripción de los tratamientos con indicación de la técnica de aplicación y de los materiales y productos a emplear.

- Descripción de las acciones complementarias a desarrollar sobre el entorno(microclima e iluminación -natural, artificial o mixta) y sobre el edificio, entendido como contenedor (sistemas de anclaje del la arquitectura de los retablos a los muros, actuaciones puntuales en ellos, instalación de doble puerta, evacuación, sistemas de seguridad, etc),

- Elaboración de un cronograma de actuación, con su respectivo faseado.

- Descripción de un presupuesto desglosado de los costes y medios técnicos y auxiliares necesarios para llevar a cabo la propuesta

Un último aspecto de interés en la metodología propugnada por el I.A.P.H. viene determinada por el control y el mantenimiento tanto de las obras como del medio ambiente con objeto de examinar su evolución temporal y detectar a tiempo cualquier variación o alteración que pueda incidir en la conservación de los bienes intervenidos. Es por ello que concluirá con la elaboración de una propuesta adecuada de mantenimiento que se definirá en base a los resultados de los estudios previos. 